\title{
Effects of high-latitude atmospheric gravity wave disturbances on artificial HF radar backscatter
}

\author{
A. Senior ${ }^{1}$, M. J. Kosch ${ }^{1}$, T. K. Yeoman ${ }^{2}$, M. T. Rietveld ${ }^{3}$, and I. W. McCrea ${ }^{4}$ \\ ${ }^{1}$ Dept. of Communication Systems, Lancaster University, Lancaster, LA1 4WA, UK \\ ${ }^{2}$ Dept. of Physics and Astronomy, University of Leicester, Leicester, LE1 7RH, UK \\ ${ }^{3}$ EISCAT Scientific Association, Ramfjordmoen, 9027 Ramfjordbotn, Norway \\ ${ }^{4}$ Space Science and Technology Division, Rutherford Appleton Laboratory, Chilton, OX11 0QX, UK
}

Received: 23 December 2005 - Revised: 15 June 2006 - Accepted: 4 July 2006 - Published: 20 September 2006

Part of Special Issue "Twelfth EISCAT International Workshop"

\begin{abstract}
Observations of HF radar backscatter from artificial field-aligned irregularities in an ionosphere perturbed by travelling disturbances due to atmospheric gravity waves are presented. Some features of the spatio-temporal structure of the artificial radar backscatter can be explained in terms of the distortion of the ionosphere resulting from the travelling disturbances. The distorted ionosphere can allow the HF pump wave to access upper-hybrid resonance at larger distances from the transmitter than are normally observed and can also prevent the pump wave reaching this resonance at close distances. The variation in altitude of the irregularities sometimes results in a significant variation in the elevation angle of arrival of the backscattered signal at the radar implying that the radar "sees" a target moving in altitude. We suggest that this may be evidence of off-orthogonal scattering from the irregularities.
\end{abstract}

Keywords. Ionosphere (Active experiments; Ionospheric disturbances; Ionospheric irregularities)

\section{Introduction}

Atmospheric gravity waves (AGW) have been the subject of much investigation (see the reviews by Yeh and Liu, 1974; Francis, 1975; Hunsucker, 1982 and Hocke and Schlegel, 1996). These waves in the neutral atmosphere are commonly observed indirectly by their ionospheric signatures known as travelling ionospheric disturbances (TIDs). The TID takes the form of a wave-like perturbation in the plasma density which is mainly due to the neutral wind perturbation of the AGW dragging the plasma along the magnetic field and at the

Correspondence to: A. Senior

(a.senior@lancaster.ac.uk) same time compressing or expanding it. The detailed interaction between the AGW and the ionosphere has been examined by Hooke (1970a,b); Kirchengast et al. (1996), amongst others.

AGWs and TIDs can be broadly classified into two categories, depending on their horizontal wavelength (Hunsucker, 1982). Medium-scale waves have wavelengths of several hundred kilometres, periods in the 15-60-min range and horizontal speeds of $100-250 \mathrm{~m} \mathrm{~s}^{-1}$. Large-scale waves have wavelengths of more than $1000 \mathrm{~km}$, periods in the $30-180-$ min range and horizontal speeds of $400-1000 \mathrm{~m} \mathrm{~s}^{-1}$. At high-latitudes, the waves are thought to be mainly excited by variations in Joule heating or Lorentz forcing associated with electrojet currents (Chimonas and Hines, 1970), although other possibilities, including heating from particle precipitation have been considered (Hunsucker, 1982).

According to theory (Mayr et al., 1990) the waves may propagate directly in the thermosphere; with guidance from the temperature gradient at the base of the thermosphere; by reflection from the ground or by trapping between the ground and lower thermosphere. The large-scale waves suffer less attenuation than the medium-scale waves and so are dominant at large distances from the source. Since dissipation is less in the lower atmosphere, the earth-reflected mode is important for the medium-scale waves as it permits propagation to longer distances. For an impulsive source at E-region heights (from an electrojet, for example), Francis (1974) showed that the earth-reflected medium-scale waves exhibit dispersion effects which result in a train of wave cycles being observed away from the source. The direct waves retain the impulsive character of the source.

A number of observational techniques have been applied to TIDs - see the review articles cited earlier. For the purposes of the present results, the most relevant techniques are

Published by Copernicus GmbH on behalf of the European Geosciences Union. 
the use of HF coherent scatter radars and incoherent scatter radars. TIDs leave spatial and temporal signatures in the power returned by backscattering of an HF radar signal from the ground after reflection from the disturbed ionosphere. These periodic power variations are produced by the focussing and defocussing of the radar beam by the electron density perturbations in the ionosphere produced by the TID. Samson et al. (1990) presented observations of such power variations which they interpreted as being due to equatorward propagating earth-reflected gravity waves. They were able to determine the horizontal wavelength, direction of propagation and phase speed of the waves from their observations. Bristow and Greenwald (1995) developed an approach to allow the estimation of the TID amplitude in terms of the electron density perturbation from the ground backscatter power variations. They found that the electron density perturbations were on the order of 20-35\%. Arnold et al. (1998) adopted a different approach to interpreting the ground backscatter observations. Instead of using the backscatter power variations, they examined the variation in the range to the edge of the skip zone, the region of the Earth's surface from which ground backscatter cannot be obtained because the radar wave takeoff elevation angle required to reach inside the zone is so high that the wave penetrates the ionosphere (Davies, 1965). This range is modulated by the varying ionospheric electron density. They compared their measurements, made with the HF radar at Hankasalmi, Finland with electron density measurements from the EISCAT UHF radar near Troms $\varnothing$, Norway and found good correlation between the skip distance variation and the electron density variation at a height of $235 \mathrm{~km}$. We use the same instrumentation in the present study.

Incoherent scatter radar has also proven to be an important method for studying gravity waves. Most obviously, the vertical structure of the electron density perturbation is revealed, but perturbations are seen in the other plasma parameters too. Schlegel (1986) used field-parallel ion velocities measured by the EISCAT UHF radar to investigate AGWs since the ion-neutral coupling makes this velocity a good tracer of the neutral velocity. Shibata and Schlegel (1993) also used EISCAT to examine the vertical structure of AGWs. They mainly used the ion temperature perturbation since it is closely related to the neutral temperature variation in the lower thermosphere. Their observations clearly showed the characteristic phase progression of the AGWs with altitude: downward (upward) phase propagation associated with upgoing (down-going) waves. The ability to measure the effect of the AGW on the various plasma parameters makes the incoherent scatter technique particularly valuable in understanding the AGW-TID relationship and this was exploited by Kirchengast et al. (1996) who used a computational model of the ionospheric response to the thermospheric perturbation to determine AGW properties from the "polarisation" information provided by the variations in the plasma parameters.
Artificial field-aligned irregularities with small scales (of the order of metres) transverse to the geomagnetic field are one of the most important effects produced by the action of a high-power O-mode HF pump wave on the ionospheric plasma (Gurevich, 1978; Robinson, 1989). The O-mode wave is converted to electrostatic upper-hybrid (UH) waves on density irregularities in the vicinity of the level where the pump frequency equals the plasma UH frequency. This upper-hybrid resonance (UHR) level occurs a few kilometres below the O-mode reflection altitude in typical ionospheric conditions. Excitation of the irregularities can take place from infinitesimal density fluctuations (Das and Fejer, 1979; Dysthe et al., 1983) but with larger fluctuations, trapping of the UH waves in the density depletions becomes important (Mjølhus, 1983; Dysthe et al., 1982).

The saturation of the instability probably depends on a number of factors such as anomalous absorption of the pump wave (Robinson, 1989), the nonlinear increase in field-parallel thermal conductivity with electron temperature (Gurevich et al., 1995) and possibly destruction due to drift waves excited by the steep temperature and density gradients associated with the irregularities (Antani and Guzdar, 1999; Borisov, 2004).

The electron density fluctuations associated with the irregularities are effective at backscattering radio waves and so radar techniques are important for investigating the irregularities. As a result of field-parallel diffusion being much greater than field-transverse diffusion, the irregularities are highly field-aligned. This results in the radar scattering being highly aspect-sensitive and backscatter is only observed when the radar beam is close to orthogonality with the geomagnetic field. This property was discovered in the early work with the heater at Platteville, Colorado, USA (Thome and Blood, 1974; Fialer, 1974; Minkoff et al., 1974). Insitu rocket measurements (Kelley et al., 1995; Franz et al., 1999) seem to confirm this picture. Franz et al. (1999) suggested that the elongation ratio of the irregularities could be 5000 or more and in modelling radar backscatter based on their in-situ measurements, they assumed infinite fieldalignment and therefore infinite aspect sensitivity. Senior et al. (2004) also assumed infinite aspect sensitivity in estimating the field-parallel length scale of the irregularities from multi-frequency HF radar measurements.

Blagoveshchenskaya and Troshichev (1996) presented observations of artificial F-region irregularities by continuouswave HF Doppler sounding. They found oscillations in the Doppler frequency with periods of $12-25 \mathrm{~min}$ which they suggested could be the effects of medium-scale TIDs in the heated ionosphere. In this paper we describe an experiment in which artificial F-region irregularities were observed with a HF coherent scatter radar under conditions when the ionosphere above the HF pump transmitter was disturbed by travelling ionospheric disturbances caused by atmospheric gravity waves. Our primary concern will be with the effects of the TIDs on the artificial irregularities and not with the TIDs 
themselves. We show how the key features of the radar observations can be explained by how the access of the pump wave to upper-hybrid resonance is modified by the distortion of the ionosphere and we discuss the evidence provided by the observations concerning the characteristics of the artificial irregularities themselves.

\section{Instrumentation and observations}

During the interval 10:00-14:00 UT on 3 December 2004, the CUTLASS HF coherent scatter radar (Lester et al., 2004) at Hankasalmi, Finland $\left(62.32^{\circ} \mathrm{N}, 26.61^{\circ} \mathrm{E}\right)$ observed artificial field-aligned irregularities (AFAI) in the F-region induced by the EISCAT HF facility (Rietveld et al., 1993) located at Ramfjordmoen, Norway $\left(69.58^{\circ} \mathrm{N}, 19.22^{\circ} \mathrm{E}\right)$. The HF facility operated on a $60 \mathrm{~s}$ on, $120 \mathrm{~s}$ off cycle, transmitting an $\mathrm{O}$-mode wave at $12^{\circ}$ south of the vertical in the magnetic meridian plane; approximately in the direction of the geomagnetic field in the F-region. The pump frequency was 4.544 MHz between 10:00 UT and 13:55 UT. From 13:55 UT to $14: 13 \mathrm{UT}$, the pump frequency was $4.04 \mathrm{MHz}$. However, the ionosphere had already weakened sufficiently by 13:55 UT that no heating effects were seen. The effective isotropic radiated power was $100 \mathrm{MW}$ and the beam fullwidth at half-maximum power was $11.3^{\circ}$. The CUTLASS radar operated in stereo mode with channel A observing a single beam in the direction of the HF facility. The radar frequency was cycled over 10 frequency bands from approximately 9-20 MHz, with a nominal $1 \mathrm{~s}$ dwell time on each band. Seventy $15-\mathrm{km}$ range gates were used with the nominal first gate at $480 \mathrm{~km}$ from the radar. The channel B observations will not be discussed here. Figure 1 shows the location of the HF facility, the CUTLASS radar and the radar fieldof-view.

The top three panels of Fig. 2 show the CUTLASS backscatter signal-to-noise ratio (SNR) versus range and time for sounding frequencies of $13.2,15.1$ and $18.0 \mathrm{MHz}$. In the group range interval $800-1100 \mathrm{~km}$, strong periodic backscatter enhancements due to AFAI can be seen. Beyond $1200 \mathrm{~km}$ on $13.2 \mathrm{MHz}$, strong ground scatter returns are observed. These ground scatter returns exhibit quasi-periodic modulation of the skip distance.

The backscatter from the AFAI also shows strong modulation in both location and intensity with time. The most prominent perturbations occur in the intervals 11:3012:00 UT ("C" in Fig. 2; the significance of this annotation will become clear in due course) and 12:30-13:00 UT ("E") when AFAI-induced backscatter appears at around $1100 \mathrm{~km}$ and then seems to travel towards the radar, merging with the bulk of the artificial backscatter and then emerging and travelling towards $750 \mathrm{~km}$ before vanishing. The characteristics of these perturbations vary with frequency. For example, at $18.0 \mathrm{MHz}$, the equatorward projection of the disturbances (closer than about $850 \mathrm{~km}$ ) is absent; in

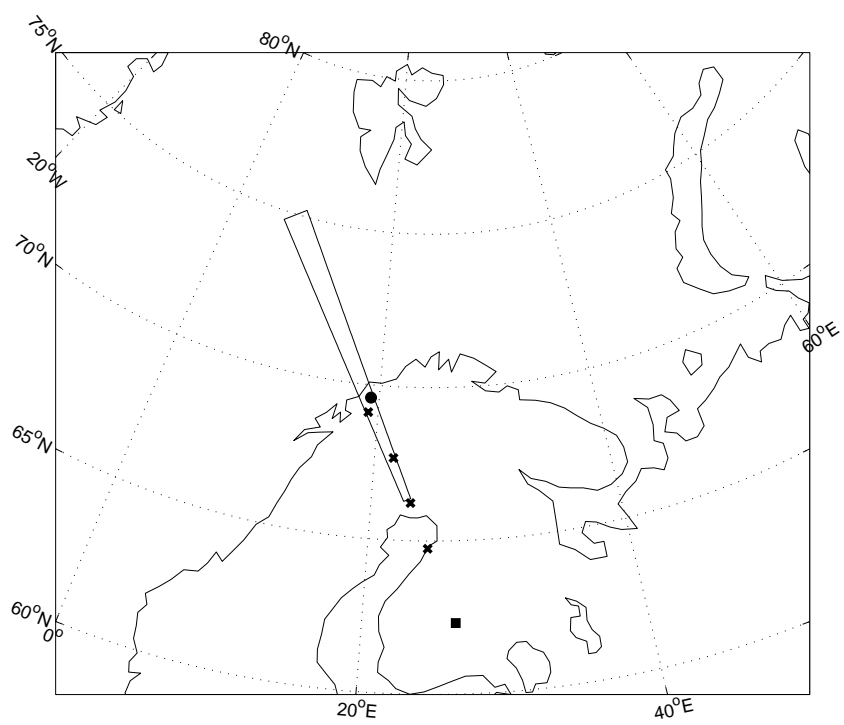

Fig. 1. Map of the instruments used and their fields-of-view. The square denotes the CUTLASS Hankasalmi radar. The box represents the field-of-view of channel A (beam 5). The circle denotes the EISCAT UHF radar and EISCAT HF facility. The crosses indicate the UHF radar scan positions at an altitude of $250 \mathrm{~km}$.

addition, at $13.2 \mathrm{MHz}$, the second perturbation produces a strong, localised enhancement in backscatter power between about 850 and $1000 \mathrm{~km}$ during the interval 12:3012:45 UT, whereas a similar enhancement seems to occur slightly earlier and over the range interval from 900-1050 km at $15.1 \mathrm{MHz}$ and is not obvious at all at $18.0 \mathrm{MHz}$. Besides these two large perturbations, similar, less dramatic effects can be seen in the artificial backscatter at other times ("A", "B", "D", and "G").

During this interval of observation, the EISCAT UHF incoherent scatter radar (Rishbeth and van Eyken, 1993), colocated with the HF facility, was observing the ionosphere. The radar performed a $360 \mathrm{~s}$ scan cycle in which the antenna moved between four pointing directions. This included the nominal F-region "field-aligned" position of $184.0^{\circ} \mathrm{az}$ imuth, $77.1^{\circ}$ elevation. The radar dwelled on this position for $30 \mathrm{~s}$ before the UT 6-min boundary when the HF facility pump wave was switched on and continued to dwell for a further $60 \mathrm{~s}$ until the pump was switched off. Since the UHF radar cycle was twice as long as the pump cycle, only every second pump cycle was observed with the UHF radar pointing into the pumped plasma. At other times, the UHF radar made measurements at lower elevations in the direction of the CUTLASS radar site. The radar was pointed on an azimuth of $154.1^{\circ}$, towards Hankasalmi at elevations of $45.1^{\circ}, 28.8^{\circ}$ and $20^{\circ}$. These positions were chosen to give an equal horizontal spacing of $\sim 175 \mathrm{~km}$ at an altitude of $250 \mathrm{~km}$. The dwell time increased from $30 \mathrm{~s}$ at $45.1^{\circ}$ elevation to $75 \mathrm{~s}$ at $20^{\circ}$ elevation in order to mitigate the effects of the reduced signal-to-noise ratio due to the increased distance 


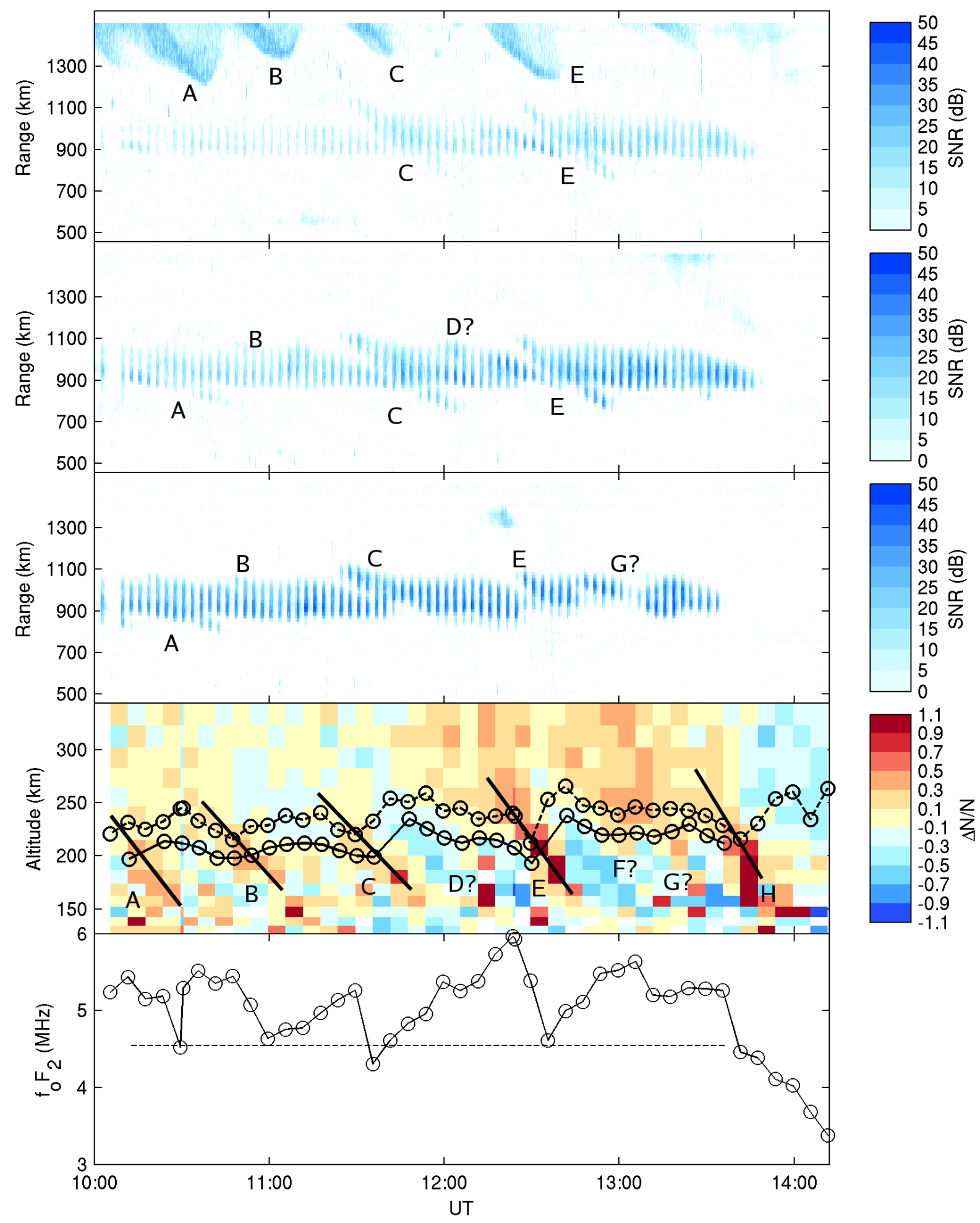

Fig. 2. Top panel: range-time-intensity (RTI) plot of CUTLASS radar backscatter signal-to-noise ratio (SNR) at $13.2 \mathrm{MHz}$. Second panel (from top): as top panel, but at $15.1 \mathrm{MHz}$. Third panel: as top panel, but at $18.0 \mathrm{MHz}$. In these three panels, the range is the group range measured by the radar, not ground range. Fourth panel: relative electron density perturbations measured by the EISCAT UHF radar in the field-aligned direction. The solid black line indicates the altitude of the HF pump-enhanced ion line and the dashed black line indicates the altitude of the F-region density maximum. Bottom panel: the solid line indicates the F-region O-mode critical frequency. The dashed line is the HF pump frequency. 
to the scattering volume at a given altitude. The scan pattern was intended to allow a 2-D section of the ionosphere along the Hankasalmi-Troms $\varnothing$ path to be reconstructed for the purpose of raytracing the HF radar beam. Fig. 1 shows the UHF radar scan positions at an altitude of $250 \mathrm{~km}$.

The solid line in the fourth panel of Fig. 2 shows the altitude at which the HF-pump-enhanced ion line was observed by the UHF radar when in the field-aligned pointing direction. This enhancement in incoherent backscatter power is due to ion-acoustic waves stimulated by the HF pump wave and occurs close to the reflection height of the HF pump wave (Stubbe et al., 1992). It is thus a proxy for the pump reflection height. The location of the enhancement was determined by inspection of profiles of the backscatter power in the $12 \mu \mathrm{s}$ fractional lag (the shortest non-zero lag) of the alternating code in the tau $2 \mathrm{pl}$ radar program. This gives a range resolution of $\sim 1.8 \mathrm{~km}$. The enhancement is usually well-defined and so we estimate an error of $\pm 2 \mathrm{~km}$ in assigning it to a particular altitude.

The pump reflection altitude inferred from the black line initially shows a periodic variation with a range of about $15 \mathrm{~km}$. At about 11:45 UT there is a large increase in reflection altitude of $35 \mathrm{~km}$. Thereafter, the reflection altitude drops, with some fluctuation until an even larger increase of $45 \mathrm{~km}$ occurs at about 12:42 UT. The reflection altitude then drops again and fluctuates until 13:42 UT. After this time, no ion-line enhancements were detected, which is probably because the plasma density had fallen too low for the HF pump wave to interact. It is also worth noting that no enhancements were seen during the pump-on periods at 11:48 and 12:42 UT, during the intervals where the reflection height appeared to jump dramatically upwards.

The fourth panel of Fig. 2 also shows relative electron density perturbations $(\Delta N / N)$ versus altitude and time measured by the UHF radar in the field-aligned pointing direction while the pump wave was off, to avoid possible contamination from heating effects. The integration time was thus $30 \mathrm{~s}$. The relative perturbation was computed by subtracting a linear fit to the density time series at each altitude and then dividing the residuals by this fit. The relative error in the electron density $N$ according to the radar analysis software was less than 0.1 (and often less than 0.05) in the altitude range $200-350 \mathrm{~km}$. Below $200 \mathrm{~km}$, the relative error increased and was more variable, but was usually below 0.2. As the radar measurement is not absolute, the electron densities were calibrated against the EISCAT Dynasonde and found to agree within about $10 \%$.

A number of quasi-periodic, sloping features can be seen in the plot of electron density perturbations. In the interval 10:00-12:00 UT, these are most prominent between about 170 and $280 \mathrm{~km}$, with the largest variation at around $190 \mathrm{~km}$. The density perturbation here oscillates between about +0.3 and -0.2 with a period of $\sim 1800-2400 \mathrm{~s}$. Three peaks labelled A, B and C can be seen in this interval and these coincide with the minima in the altitude of the enhanced ion- line. The third peak, around 11:30 UT, is followed by the first large increase in pump reflection height. The relative density perturbation here varies from around +0.5 to -0.3 (or maybe more) and is thus somewhat more intense than the preceding two. Between 12:00 and 13:00 UT a much more intense sloping perturbation can be seen, varying between about +0.8 and -0.5 at its most intense around $190 \mathrm{~km}$ at $12: 45 \mathrm{UT}$ (E). Before this, around 12:15 UT there is perhaps evidence of a weaker sloping perturbation (D), particularly at $200 \mathrm{~km}$ and above, though this is unclear due to large fluctuations in the electron density profile at 12:12 UT. Also, after 13:00 UT, there is evidence of three more perturbations, the final one around 13:45 UT $(\mathrm{H})$ stronger than the first two (F and G) and more evident at lower altitudes. The first of these does not seem to have any significant associated reflection height change, whereas the second shows a small peak at 13:30 UT. The final one $(\mathrm{H})$ coincides with the weakening of the ionosphere resulting in no further ion line enhancements.

To set the observations in context, the dashed line in the fourth panel of Fig. 2 represents the altitude of the F-region density peak. The bottom panel of the figure shows the F-region O-mode critical frequency and how this compares to the pump frequency in use during the experiment $(4.544 \mathrm{MHz})$. These parameters were determined from the UHF radar electron density profiles. The dramatic weakening of the ionosphere after about 13:30 UT is clearly seen in the critical frequency.

Finally, in Fig. 3, we present elevation angle-of-arrival measurements for the HF radar backscatter. The top, middle and bottom panels correspond to sounding frequencies of $13.2,15.1$ and $18.0 \mathrm{MHz}$ respectively, analogous to the top three panels of Fig. 2. The elevation angle is determined by comparing the phase of the received signal between the main antenna array and the secondary interferometer array in the manner described by Milan et al. (1997). The absolute phase difference between receive paths of the two arrays is affected by an offset due to the receiver electronics, which causes a systematic error in the elevation angles. In order to compensate for this phase offset, a phase correction was empirically computed so that the elevation angles of the main body of scatter (not including the large perturbations $\mathrm{C}$ and $\mathrm{E}$, for example) were close to those predicted by a raytracing calculation. The ionospheric model used in the raytracing was a 2-D "slice" along the HF radar path determined from the four UHF radar scan positions. Thus, it should be borne in mind that the elevation angles presented here have been post-processed in this way and are not therefore truly independent measurements. Nevertheless, it is expected that at least the relative differences between angles on a given frequency should be realistic and that is all that we shall require in our analysis.

Figure 3 shows that on all frequencies, the large perturbations " $C$ " and " $E$ " cause increases in the elevation angle of the backscattered signal. The change is particularly strong at 13.2 MHz, where the angle increases from $\sim 6^{\circ}$ to $\sim 22^{\circ}$. At 


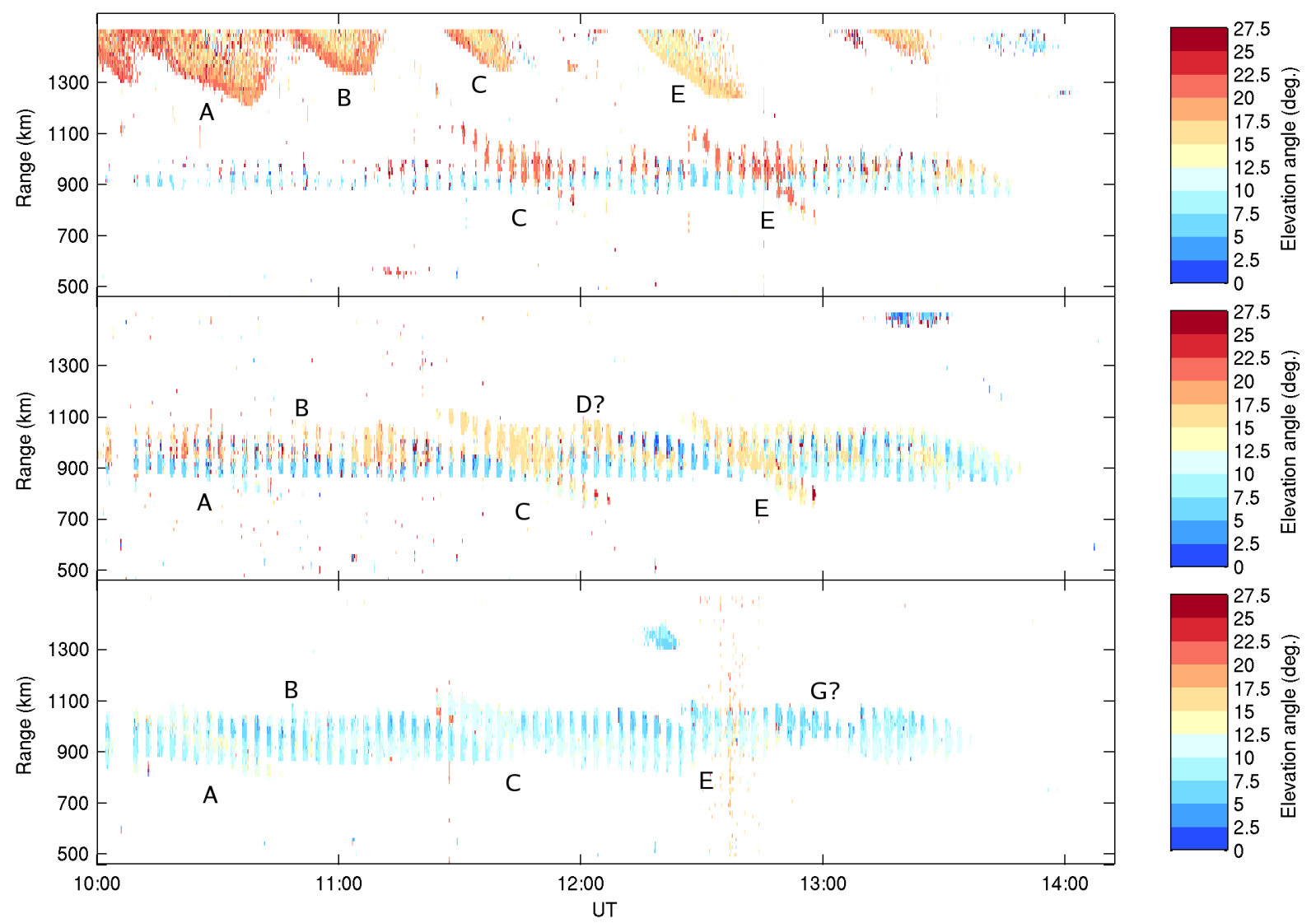

Fig. 3. Elevation angle measurements from the CUTLASS HF radar. Top panel: $13.2 \mathrm{MHz}$; centre panel: $15.1 \mathrm{MHz}$; bottom panel: 18.0 MHz. The frequencies and time intervals correspond to the backscatter SNR data in the top three panels of Fig. 2.

$15.1 \mathrm{MHz}$, the change is from $\sim 7^{\circ}$ to $\sim 16^{\circ}$ and at $18.0 \mathrm{MHz}$ the change is much less, from $\sim 8^{\circ}$ to $\sim 12^{\circ}$. It is also evident that the smaller perturbations produce variations in the elevation angles. The significance of these apparent changes in elevation angle will be discussed later.

The geophysical conditions on the day the observations were made were very quiet; $K_{p}$ ranged from $0^{+}$to $1^{-}$during the interval 00:00 UT to 15:00 UT and $D_{s t}$ ranged from -28 to $-21 \mathrm{nT}$ during the same interval.

\section{Discussion}

\subsection{The gravity wave/TID signatures}

The ground scatter skip distance variations in the top panel of Fig. 2 are very similar to those discussed by Arnold et al. (1998) and strongly suggest atmospheric gravity wave activity creating travelling ionospheric disturbances (TIDs), travelling in a direction with a component towards the CUTLASS radar. Considering the skip distance involved, it seems highly likely that the disturbance causing the skip distance variation will also pass through the ionosphere over the EISCAT site, since this is approximately mid-way between the CUTLASS radar and the edge of the skip zone and therefore close to where the radar rays are refracted back to earth in the F-region.

This idea is supported by the EISCAT UHF radar observations in the fourth panel of Fig. 2. The density perturbations in the lower panel show the classic behaviour expected from a gravity-wave-induced TID (Shibata and Schlegel, 1993). The sloping features in which the density perturbation propagates down from higher to lower altitudes with time are what would be expected from a gravity wave with downward-sloping phase fronts passing through the thermosphere over the radar. From these density perturbations, we may estimate the vertical wavelength $\lambda_{z}$ and vertical phase speed $v_{z}$ of the gravity wave/TID. For the negativegoing half-cycle of the perturbation between about 11:30 and 12:00 UT, we obtain from Fig. $2 \lambda_{z} \approx 160 \mathrm{~km}, T \approx 2200 \mathrm{~s}$ and hence $v_{z} \approx-70 \mathrm{~m} \mathrm{~s}^{-1}$, where the negative sign indicates downward propagation. For the more intense negativegoing half-cycle between 12:30 and 13:00 UT we obtain $\lambda_{z} \approx 140 \mathrm{~km}, T \approx 1800 \mathrm{~s}$ and hence $v_{z} \approx-80 \mathrm{~m} \mathrm{~s}^{-1}$. These two half-cycles have rather similar vertical dispersion characteristics. Note that we are assuming there is no significant 
background vertical plasma drift or neutral wind. As Shibata and Schlegel (1993) pointed out, this can lead to a significant error in estimating the true wave parameters because of the Doppler shift arising from the neutral wind. Fortunately, in this study the apparent wave parameters are sufficient to allow us to interpret the observations.

Comparing the density perturbation in the fourth panel of Fig. 2 with the CUTLASS ground scatter returns in the top panel, we can associate the skip distance perturbations with the density perturbations rather well. The density perturbations in the fourth panel of Fig. 2 have been labelled A-H. Note that the identification of $\mathrm{D}$ and $\mathrm{F}$ is somewhat unclear. By comparing the relative timing of these to the timing of the skip distance perturbations, we have assigned the same labels to what we believe are the corresponding skip distance perturbations. The weak density perturbations $\mathrm{D}, \mathrm{F}$ and $\mathrm{G}$ do not have any obvious signature in the CUTLASS data, but the skip distance might simply be beyond the range of the observations. The larger perturbation $\mathrm{H}$ has no obvious signature either. This may be partly due to the collapse in ionospheric densities after $\sim 13: 30$ UT causing the average skip distance to increase to well beyond the range of observation.

The fact that the density perturbations seem to associate with the skip distance perturbations suggests that they are indeed the density signatures of the TIDs travelling with a component towards the CUTLASS radar. This confirms that the TIDs do indeed pass through the ionosphere over the EISCAT site and hence may influence the production of AFAI by the HF facility. Indeed, the information on the height of the enhanced ion-line in the fourth panel of Fig. 2 suggests that the density perturbations lead to rather large variations in the pump reflection altitude. The AFAI are produced around the upper-hybrid resonance (UHR) altitude which is located slightly (typically a few kilometres) below the reflection altitude, thus we can can expect the location of the AFAI to vary in altitude as the TID passes through the pumped volume of plasma.

What is surprising are the large horizontal extensions of the AFAI backscatter regions associated particularly with TIDs $\mathrm{C}$ and E. It appears that as the TIDs approach the HF facility, AFAI is produced a great distance $(\sim 200 \mathrm{~km})$ poleward of the centre of the normal AFAI region. This extension moves towards the normal region and merges with it, subsequently to emerge on the equatorward edge and continue to approach the radar to a range of about $200 \mathrm{~km}$ closer than the centre of the normal region. This means that overall, the heater is able to excite AFAI over a range interval of around $400 \mathrm{~km}$ (but not simultaneously). This is very much greater than the $\sim 200 \mathrm{~km}$ normally observed (Bond et al., 1997; Robinson et al., 1998). As the AFAI backscatter extensions are approaching the poleward edge of the normal AFAI region, the poleward edge of the normal region sometimes appears to be "eroded".

In order to estimate the horizontal dispersion characteristics of the gravity waves/TIDs, we examined the UHF radar measurements made at the $45.1^{\circ}$ elevation direction towards Hankasalmi. A plot of relative electron density perturbations (not shown) computed in the same way as the fourth panel of Fig. 2 revealed very similar-looking perturbations. Perturbations A, B, C, E and $\mathrm{H}$ could be identified. At an altitude of $190 \mathrm{~km}$, the positive peaks of these perturbations occurred approximately $1500 \mathrm{~s}$ later at the $45.1^{\circ}$ elevation position than at the field-aligned position. The horizontal distance between radar scan positions at $190 \mathrm{~km}$ is $150 \mathrm{~km}$ and so the component of the TID phase speed along the direction of the EISCAT-CUTLASS path is $\sim 100 \mathrm{~m} \mathrm{~s}^{-1}$. This direction is nearly meridional $\left(20^{\circ}\right.$ west of geographic north; see Fig. 1). Based on the periods estimated earlier, we conclude that the component of the horizontal wavelength in the direction of the EISCAT-CUTLASS path for perturbations C and $\mathrm{E}$ is respectively $\sim 220 \mathrm{~km}$ and $\sim 180 \mathrm{~km}$. The four UHF radar scan positions are (almost) collinear and so we cannot estimate the propagation direction of the TID from these measurements.

Besides the backscatter power and elevation angle measurements, the CUTLASS radar also measures the line-ofsight velocity of the irregularities and it may be thought that these could add additional information to the picture of the TIDs. We have chosen not to include these measurements because firstly the relationship between the line-of-sight velocity of the irregularities and the TID parameters is not straightforward (as the following sections go some way to indicate) and secondly because the measurements are also affected by other phenomena, particularly $\boldsymbol{E} \times \boldsymbol{B}$ drift due to magnetospheric ULF waves (Yeoman and Wright, 2001) and these make interpretation difficult. A complete discussion of the TID effects on all the key parameters measured by CUTLASS is beyond the scope of this study.

On the basis of our measurements of the TID parameters, the waves would fall into the medium-scale category discussed in the Introduction. The train of wave cycles is suggestive of a dispersed earth-reflected wave from an impulsive source, but it may also arise from direct waves from a series of source impulses (Francis, 1974).

\subsection{Simulation of TID effect on HF pump propagation}

It is clear that when a TID is present in the ionosphere, the surfaces of constant plasma density are distorted due to the associated density perturbations. It seems plausible that the distorted surfaces might make it possible for the HF pump wave to excite AFAI at distances far from where this would be expected in a spherically-stratified ionosphere. In order to test this hypothesis, a raytracing simulation of the pump beam was carried out in a model ionosphere distorted by a TID. The raytracing was performed using a modified version of the Jones and Stephenson (1975) code. The original code contains a subroutine (known as WAVE2) which can be used as a simple model of a TID. A very similar model to this was used by Georges and Stephenson (1969) to simulate ground 


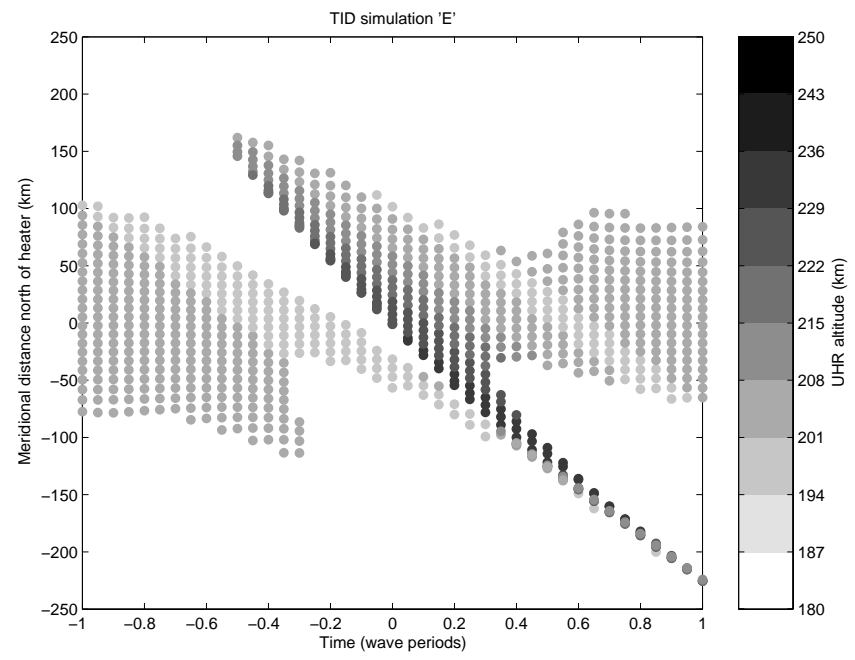

Fig. 4. Simulation of how the region where the HF pump reaches the upper-hybrid resonance altitude varies as the TID "E" passes over the transmitter location. Time zero corresponds to the time when the envelope peak is directly above the transmitter. Each circle represents the location where an up-going pump ray intersects the upper-hybrid resonance altitude.

backscatter returns from a HF radar. Note that a more sophisticated approach to modelling a gravity-wave-induced TID was adopted by Huang et al. (1998), who treated the electron density perturbations by modelling the ionospheric response to the thermospheric wave. Our simplified approach is sufficient to capture the main details of the observations. The Jones and Stephenson WAVE2 model expresses the gravitywave-induced electron density perturbation as follows

$N=N_{0}\left[1+\delta A_{r} A_{\theta} \cos 2 \pi\left(t^{\prime}+\left(\frac{\pi}{2}-\theta\right) R_{E} / \lambda_{x}+z / \lambda_{z}\right)\right](1)$

$A_{r}=\exp \left[-\left(\left(z-z_{0}\right) / H_{\text {wave }}\right)^{2}\right]$

$A_{\theta}=\exp \left[-\left(\left(\theta-\theta_{0}\right) / \theta_{c}\right)^{2}\right]$

$\theta_{0}=\theta_{00}+\lambda_{x} t^{\prime} v_{g x} / v_{x} R_{E}$,

where $N_{0}$ is the undisturbed background electron density, $\delta$ is the amplitude of the perturbation, $\lambda_{x}, \lambda_{z}$ are the horizontal (meridional) and vertical wavelengths of the wave, $\theta$ is colatitude and $R_{E}$ is the radius of the Earth. The factors $A_{r}$ and $A_{\theta}$ determine the amplitude variation with altitude $z$ and latitude; the peak height is $z_{0}$ and the peak co-latitude $\theta_{0}$. The scale height of the amplitude is $H_{\text {wave }}$ and the scale latitude is $\theta_{c}$. The variable $t^{\prime}$ represents time in units of the wave period. The final equation represents the horizontal group propagation of the wave envelope with speed $v_{g x}$. The horizontal phase speed is $v_{x} . \theta_{00}$ is the starting co-latitude of the envelope peak at $t^{\prime}=0$.

The background electron density was represented by an $\alpha$-Chapman layer, with scale height, peak height and peak density independent of position. The geomagnetic field was included in a dipole approximation and dipole co-ordinates were used in the calculations. Therefore, $\theta$ is dipole colatitude and the TID propagates along the magnetic meridian. From our observations, we cannot be sure how realistic this is.

We first concentrate on the largest perturbation "E" in Fig. 2. Referring to the fourth panel of Fig. 2, we have $\delta \approx 0.65, z_{0} \approx 190 \mathrm{~km}, H_{\text {wave }} \approx 60 \mathrm{~km}$ and (from Sect. 3.1) $\lambda_{z} \approx 140 \mathrm{~km}$. We take $\lambda_{x}=200 \mathrm{~km}$. Now, from Fig. 2, we see that " $E$ " is relatively isolated from the adjacent parts of the wave train; the preceding (tentative) perturbation " $D$ " and the succeeding ' $F$ ' are both rather weak in comparison. Thus we make use of the factor $A_{\theta}$ to localise the perturbation in the model by taking $\theta_{c}=1^{\circ}$. Furthermore, we choose the horizontal group speed $v_{g x}$ equal to the horizontal phase speed $v_{x}$ so that the waveform retains the same shape as it travels over the HF pump transmitter. Both speeds are taken as $100 \mathrm{~m} \mathrm{~s}^{-1}$ and so we neglect dispersion in the AGW/TID propagation. We centre the envelope on the negative-going zero-crossing of the density perturbation waveform in order to best model the density perturbation "E".

The background $\alpha$-Chapman layer was chosen to have a peak height of $240 \mathrm{~km}$, a scale height of $30 \mathrm{~km}$ and a peak plasma frequency of $5.4 \mathrm{MHz}$. These parameters were based on the EISCAT radar measurements. The raytracing was then carried out for time increments of 0.05 of a wave period over the range from -1 to 1 (two wave periods). The HF pump rays launched in the magnetic meridian plane were traced for $1^{\circ}$ steps of elevation from $45^{\circ}$ to the zenith. Finally, the points where the up-going rays intersected the UHR level were determined. The results are shown in Fig. 4.

It is immediately clear that the figure shows some strong similarities to the HF radar backscatter RTI plots in the top three panels of Fig. 2. A poleward projection of the region where UHR is attained by the pump wave appears as the TID approaches the pump transmitter and then merges with the normal band of UHR within $\pm 100 \mathrm{~km}$ of the transmitter, finally emerging again and projecting equatorward as the TID progresses. At the same time as the TID is approaching, a clear erosion of the region where UHR is attained is seen, creating a narrow V-shaped "notch" on the poleward side of the main backscatter region. This explains the absence of backscatter in a similarly-shaped region in the RTI plots, since the pump is unable to excite AFAI in this region. The passage of TID "E" creates a very strong change in UHR altitude, which agrees with the observed change in the height of the enhanced ion line, since both are correlated with change in pump reflection height. Weaker changes in UHR altitude are seen before and after the passage of TID " $E$ ". These are due to the weaker wave cycles preceding and succeeding " $E$ " in the model, as a result of the envelope shaping; although this was not intended, to some extent these may represent the effects of TIDs D and F.

The "erosion" effect raises an interesting question about inferring the TID speed from the HF radar backscatter RTI plot. It is evident from the observations in Fig. 2 and the 
simulation in Fig. 4 that the slope of the equatorward edge of the $\mathrm{V}$-shaped notch region of weak or no backscatter is less steep than the slope of the poleward edge (or else it would not be V-shaped). The question is, which of these slopes represents the speed of the TID? By estimating the slopes from the simulation in Fig. 4, we find that the slope of the poleward edge corresponds to a speed of $\sim 160 \mathrm{~m} \mathrm{~s}^{-1}$ whereas that of the equatorward edge corresponds to $\sim 100 \mathrm{~m} \mathrm{~s}^{-1}$. The phase and group speeds of the TID in the model were both $100 \mathrm{~m} \mathrm{~s}^{-1}$, so it appears that the equatorward edge of the notch more accurately represents the speed of the TID. Careful examination of plots of the pump raytrace (not shown) at different times during the TID passage reveal that the reason for the more rapid motion of the poleward edge (where the UHR altitude is raised) is due to the motion of the region where the pump reaches UHR relative to the TID itself, as the geometry changes. The raised UHR region travels forward relative to the TID wave and thus the total speed of this region is more rapid than the speed of the TID alone.

We now turn our attention to the weaker disturbances A and B. To simulate these, we use the same parameters as for E, except that we choose $\delta=0.25, \lambda_{x}=240 \mathrm{~km}$ and the height of the background F-region peak to be $230 \mathrm{~km}$. In addition, we do not localise the wave amplitude in latitude and let $\theta_{c} \rightarrow \infty$. The result is shown in Fig. 5, which shows two complete wave cycles.

It is evident that this simulation does not match the observations so closely. In particular, the erosion on the poleward edge of the UHR region is not mirrored in the HF radar backscatter in Fig. 2, although small poleward extensions of the backscatter region can be discerned, especially at $18.0 \mathrm{MHz}$. On the other hand, the equatorward projection of the UHR region as the TID passes is clearly seen in the data for perturbation A, if not for perturbation B.

In summary, our simple raytracing model of the pump wave propagation in a TID-perturbed ionosphere appears to reproduce the essential features of the observations. A more sophisticated model might improve the agreement in some of the details.

3.3 TID effect on HF radar observations of the artificial irregularities

Earlier, we remarked on the artificial backscatter power and elevation angle variations. We have shown how the TID affects the altitude and location at which the HF pump can reach upper-hybrid resonance. Clearly, this modification must influence the target seen by the HF radar. In addition, it is possible that the TID may have a significant effect on the radar beam propagation which could also affect how the radar views the artificial irregularities.

From theory (for example, Booker, 1956), the scattering cross-section of the artificial irregularities is proportional to $\left\langle\Delta N^{2}\right\rangle$, the mean-square electron density perturbation. The irregularities are expected to be most intense close to the

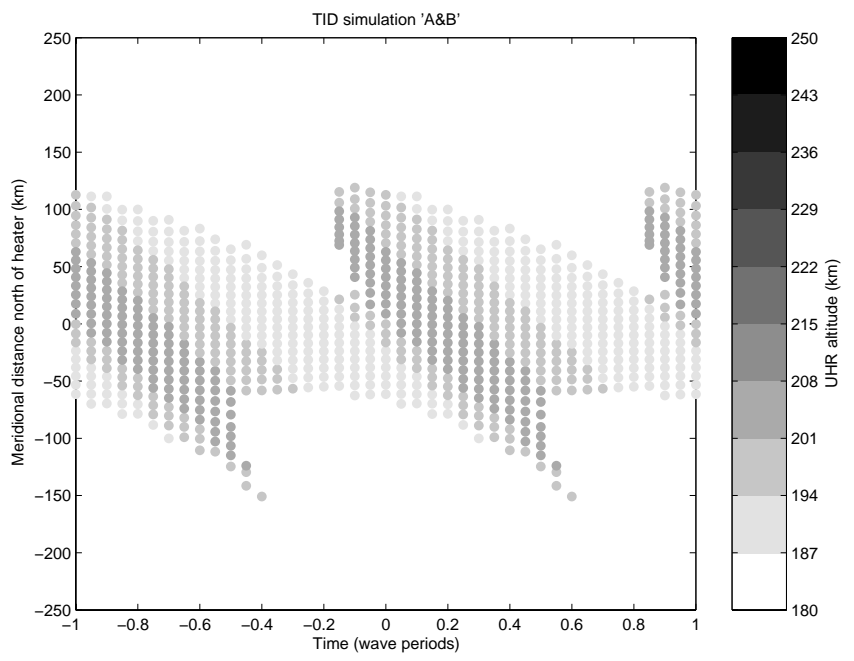

Fig. 5. As Fig. 4 but for perturbations "A" and "B".

UHR height and decay in intensity above and below due to diffusion along the magnetic field. Thus the scattering crosssection will vary in a similar way. At the same time, the scattering cross-section also depends on the radar beam aspect angle relative to the magnetic field, which determines the major axis of the irregularities. This is because, due to the more rapid diffusion along the field than across it, the wavenumber spectrum of the irregularities along the magnetic field is biased towards very small wavenumbers, whereas across the magnetic field high wavenumbers (comparable to the HF radar wavenumber) predominate. Thus, at even a small angle away from orthogonality to the magnetic field, the wavenumber spectrum rapidly shrinks towards low wave numbers and the scattering cross-section at the radar wavenumber rapidly diminishes.

Let us consider two limiting cases: (1) the irregularities are very elongated along the magnetic field and highly aspectsensitive; (2) the irregularities have little elongation and are not very aspect-sensitive. In case 1, the radar will receive backscatter only when the beam is very close to exact orthogonality to the geomagnetic field. If the irregularities move up and down in altitude, the backscatter power will vary according to the variation of the mean-square density perturbation with altitude. Assuming that the radar beam propagation is not too strongly influenced by the TID, the locus in the ionosphere where the beam reaches orthogonality does not vary. Therefore, the source location of the backscatter does not vary and in particular, the elevation angle of the backscatter (at a given range) will not vary. In other words, the radar does not "see" the height variation of the irregularities as variations in elevation angle: the target appears fixed at the location defined by orthogonality of the beam to the magnetic field.

In case 2, the radar will receive backscatter only when the beam passes very close to the location of the (short) 

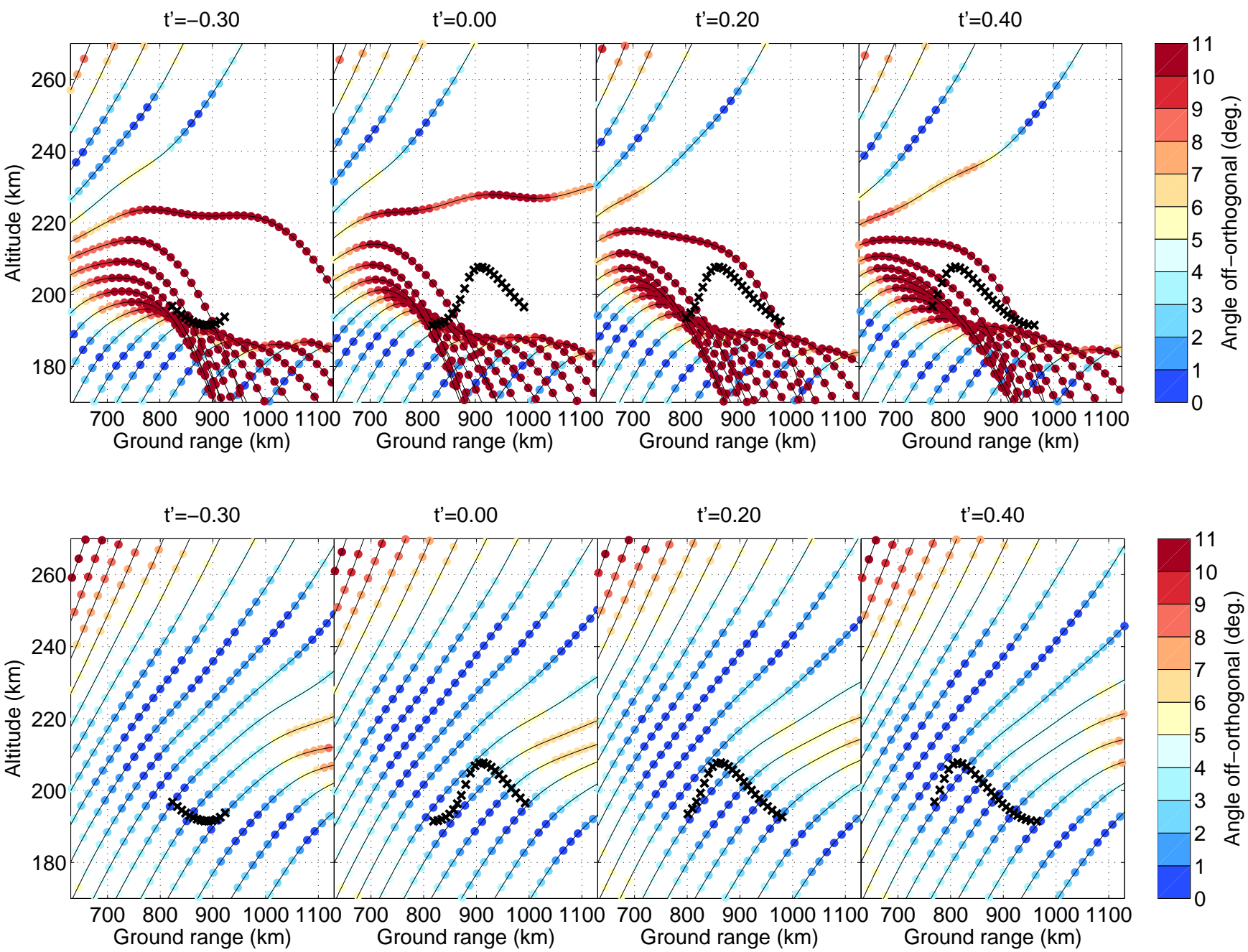

Fig. 6. Top panel: 13-MHz rays from the CUTLASS radar traced through the model ionosphere for TIDs A and B for the four times given at the top of each plot. The shaded circles on each ray indicate the angle from orthogonality. The black crosses indicate where up-going rays from the pump transmitter intersect the upper-hybrid resonance height. Bottom panel: as top panel, but for 18-MHz radar frequency.

irregularities, i.e. close to the UHR altitude. If the altitude of the irregularities varies, the backscatter power will vary according to the aspect angle of the radar beam to the irregularities at the altitude in question. Once again, assuming no strong influence of the TID on the radar beam propagation, the fact that the radar only receives backscatter from close to the altitude of the target means that the radar will now "see" the altitude variation as a variation in elevation angle. This is analogous to the simple case of straight-line propagation to a localised target.

With these cases in mind, we now apply our raytracing model additionally to the radar propagation in order to estimate the effects of the TID on the radar observations. Figure 6 shows the results of raytracing the radar beam at 13 and $18 \mathrm{MHz}$ in the model ionosphere used to simulate TIDs $\mathrm{A}$ and $\mathrm{B}$ in the previous section. The radar rays were traced at 1 degree increments of elevation angle from $5^{\circ}$ to $45^{\circ}$. The angle of the rays from orthogonality was calculated by comparing the wave normal vectors with the magnetic field direction obtained from the IGRF model for 2004 (although the dipole field model was retained in the actual raytracing calculations). The locus of UH resonance is computed by raytracing the pump wave as described in the previous section.

For a radar frequency of $13 \mathrm{MHz}$ (top panel), we see that the locus of upper-hybrid resonance always lies in a region where the radar rays are more than $10^{\circ}$ from orthogonality, either in the region of defocussed Pedersen rays or in the region of down-going, reflected rays. In case 1 above, we would expect to receive backscatter mainly from the downward extension of the irregularities from the UHR altitude towards the locus of radar beam orthogonality around 180-km 

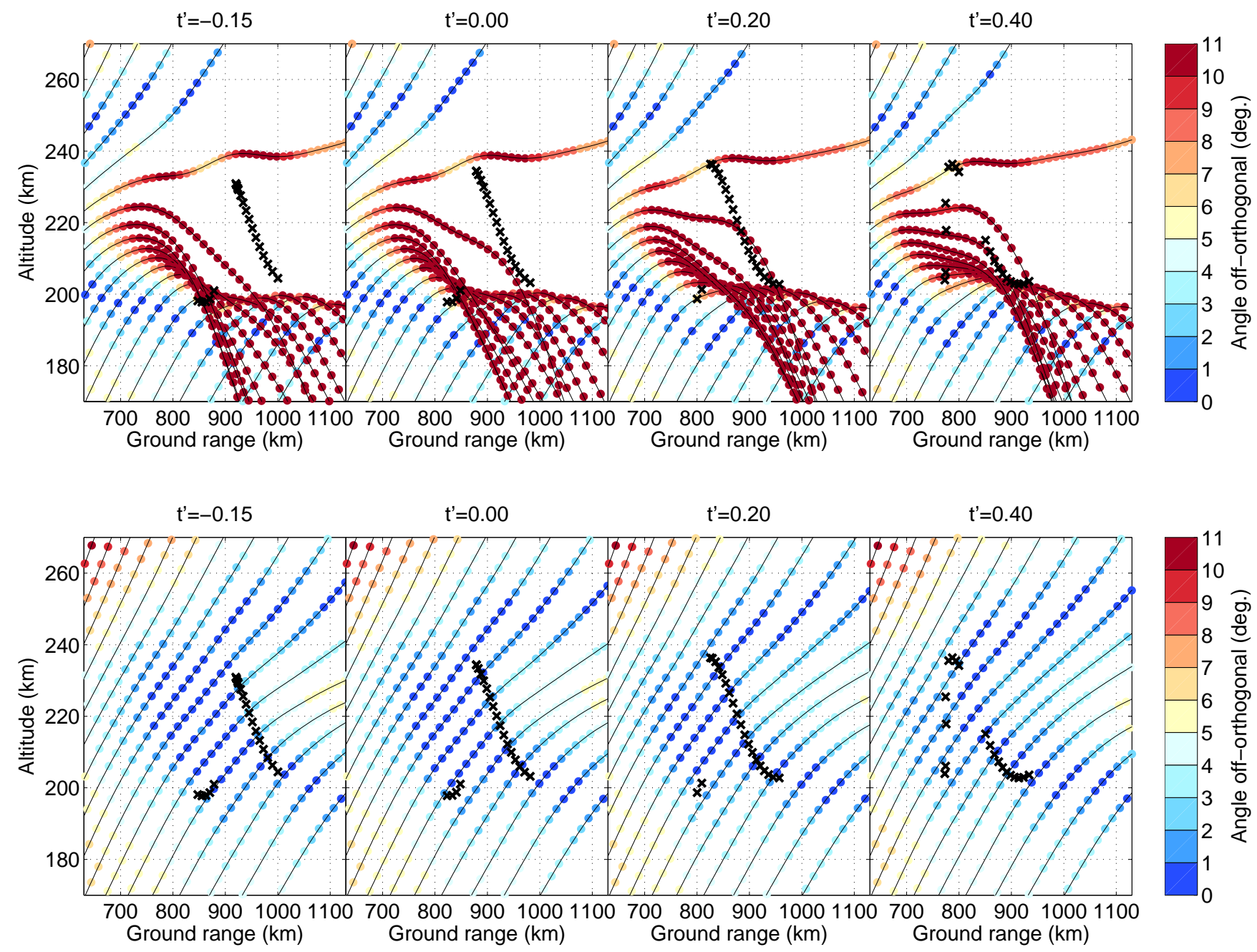

Fig. 7. As Fig. 6 but for TID "E".

altitude. In case 2 , backscatter would come from close to the UHR altitude itself. According to Fig. 2, the backscatter power on $13.2 \mathrm{MHz}$ during the passage of TIDs $\mathrm{A}$ and $\mathrm{B}$ is weak and it is difficult to discern any power variations associated with the passage of the TIDs. Likewise, in Fig. 3 it is even more difficult to detect any systematic changes in elevation angles. There are indications of higher angles at the poleward edge of the artificial backscatter, but it is not clear how these relate to the TIDs. In this case it is difficult to draw any conclusions about which, if either, of the limiting cases might be closest to the true situation.

The bottom panel of Fig. 6 shows a radar frequency of $18 \mathrm{MHz}$. The situation here is rather different. At close ranges $(\sim 850 \mathrm{~km})$, the UHR locus always lies in a region where the radar beam is about $1^{\circ}$ or less from orthogonality. However, at greater ranges $(\sim 950 \mathrm{~km})$ the radar beam at the UHR locus varies from being $3-4^{\circ}$ from orthogonality to less than $1^{\circ}$ from orthogonality as the UHR height varies with the passage of the TID. At the same time, the UHR altitude varies from about $0-10 \mathrm{~km}$ above the radar orthogonality altitude. Referring now to the observation in Figs. 2 and 3, we can see that towards the equatorward edge of the artificial backscatter, the power is relatively constant, whereas towards the poleward edge, there is a clear oscillation in the power associated with the passage of TIDs A and B. The variation is around $10 \mathrm{~dB}$ peak-peak. Comparing this with the elevation angles, whilst the angles are relatively constant towards the equatorward edge, they also show a systematic variation towards the poleward edge. The variation is around $5^{\circ}$ peakpeak and is out of phase with the variation in backscatter power.

Now, from our earlier discussion, it is clear that these observations correspond most closely with case 2 , which can explain the variation in elevation angle as a consequence of the change in altitude of UHR. However, the observed elevation angle variation of $5^{\circ}$ peak-peak does appear to be 
somewhat larger than might be expected from our raytracing. The raytracing suggests perhaps only $2-3^{\circ}$ peak-peak variation as a result of the UHR locus moving across rays. The anticorrelation of power with elevation angle is what would be expected, since higher elevation angles correspond to a higher UHR altitude which is further from radar orthogonality and gives rise to a reduced backscatter power.

Figure 7 shows a similar raytracing analysis to Fig. 6, but for the larger-amplitude TID E. We consider the lower panel, for $18 \mathrm{MHz}$ radar frequency first and once again we find that the behaviour depends on range. At closer ranges $(\sim 850 \mathrm{~km})$, the UHR locus always lies close (within $\left.1^{\circ}\right)$ to radar beam orthogonality, despite the large variations in UHR altitude. Thus in either of our limiting cases, we would not expect much change in backscatter power as the UHR altitude varies. In case 2 we might see elevation angle variations of $2^{\circ}-3^{\circ}$ as the UHR locus moves across the rays. At further ranges $(\sim 950 \mathrm{~km})$, the increase in UHR altitude would take the UHR locus away from orthogonality by $1^{\circ}-2^{\circ}$ and perhaps about $10 \mathrm{~km}$ above the locus of exact orthogonality (the increase in altitude is more easily inferred from Fig. 4). Therefore, in either limiting case we would expect to see small variations in the backscatter power and in case 2 , small variations in the elevation angle $\left(1^{\circ}-2^{\circ}\right)$.

Referring to Figs. 2 and 3, we do not see much variation with power at the further ranges, apart from that due to the erosion effect. However, elevation angles do appear to increase by $\sim 3^{\circ}$. This may again be evidence in favour of case 2 , but it is less convincing than before. At the nearer ranges, there is also erosion of the artificial backscatter. This is not expected from our raytracing. Since the backscatter is not eroded in this way on the lower frequencies, the effect must be connected to the radar propagation, not the pump propagation. A similar effect is seen to happen with TID C.

The top panel of Fig. 7 presents the raytracing for $13-\mathrm{MHz}$ radar frequency. It is immediately clear that the raised section of the UHR locus tends to lie in a region of defocussed Pedersen rays which are far from orthogonality. As the TID approaches, the part of the UHR locus nearest to the radar is depressed in altitude towards the locus of radar orthogonality at $\sim 195 \mathrm{~km}$ altitude. Thus, in either limiting case, the backscatter power might be enhanced. This could explain the localised enhancement seen in the $13.2 \mathrm{MHz}$ backscatter power in Fig. 2 as TID E approaches, and which was remarked on earlier. (A similar effect is seen at $15.1 \mathrm{MHz}$ too). Apart from this enhancement, the backscatter power does not seem obviously greater or lesser as the elevated part of the UHR locus passes over the pump transmitter. On the other hand, the elevation angles in Fig. 3 show a dramatic increase from about $6-22^{\circ}$. This might be sufficient to indicate that the backscatter is coming from rays which achieve orthogonality in the topside ionosphere in the $240-270 \mathrm{~km}$ altitude interval. This would be more consistent with an assumption of longer, more aspect sensitive irregularities (case 1). Indeed, the irregularities would have to be detectable some
10-20 km above the UHR altitude, even when the latter is at its highest. It would certainly be difficult to expect to see significant backscatter returns along the rays in the defocussed region where the transition from ionosphericallyreflected to ionospherically-penetrating rays occurs, since in addition to the defocussing, the rays are also far from orthogonality. This conclusion is supported by the elevation angles exhibited by the ground backscatter, which typically shows angles of $\sim 15^{\circ}$ at the edge of the skip zone compared to $\sim 22^{\circ}$ for the artificial backscatter from the irregularities elevated by the TID. This implies that the artificial backscatter must be coming from penetrating rays, not reflected ones.

If we suppose that case 2 above applies, we could estimate the aspect sensitivity of the striations in terms of backscatter power variation per degree off-orthogonal as $10 / 3 \approx 3 \mathrm{~dB} /{ }^{\circ}$, based on the measured backscatter power variation associated with TIDs A and B and the aspect angle variation estimated from the raytracing in Fig. 6. This is rather less than the estimate of at least $20 \mathrm{~dB}$ for $3^{\circ}$ off-orthogonal given by Fialer (1974). Alternatively, if we suppose that case 1 applies (ignoring the evidence from the elevation angles) we could estimate the decay of backscatter power with altitude as $10 / 10=1 \mathrm{~dB} \mathrm{~km}^{-1}$. This corresponds to a e-folding scale length for the mean density perturbation $\langle\Delta N\rangle$ of $\sim 8 \mathrm{~km}$. This is within the range of previous estimates, but shorter than those of Jones et al. (1984), Robinson (1989) and Senior et al. (2004).

It is difficult to separate the effects on the radar backscatter power of the elongation of the irregularities and their aspect-sensitivity. Nevertheless, our observations suggest that the irregularities may not be as highly aspect-sensitive as previously supposed. This point requires further investigation. Lower aspect-sensitivity could result from a considerable amount of additional small-scale structure along the magnetic field. Theoretical work (Antani and Guzdar, 1999; Borisov, 2004) suggests that drift waves would be excited by the high temperature and density gradients associated with the artificial irregularities. These drift waves have already been suggested as a source of very small-scale fieldtransverse structure observed in in-situ measurements (Kelley et al., 1995; Kelley, 2004), although this is probably too weak to make a significant contribution to HF radar backscatter. The turbulence associated with the drift waves would lead to additional structuring in the plasma along the magnetic field too, thus reducing aspect sensitivity. Whether this might be sufficient to account for the observed aspect sensitivity is not clear. We can make an estimate of the longitudinal scales required to explain the aspect sensitivity by considering that according to the Booker (1956) theory, for an aspect angle (off-orthogonal) of $\theta$ radians and a radar wavenumber $k$, the three-dimensional power spectrum of the irregularities must have a significant magnitude at a fieldparallel wavenumber $k_{\|} \approx 2 k \theta$. Thus for an aspect angle of $3^{\circ}$ and $k=0.4 \mathrm{~m}^{-1}(18 \mathrm{MHz})$ we have $k_{\|} \approx 0.04 \mathrm{~m}^{-1}$. This corresponds to a field-parallel wavelength of only $160 \mathrm{~m}$. Taking 
into account the strong longitudinal diffusion, this scale is very short and it is rather hard to believe that significant structure could persist at such a scale.

Another possible explanation for reduced aspect sensitivity is that there could be significant multiple-scattering of the HF radar wave in the region of artificial irregularities. In such a situation, although the "individual" irregularities may remain highly aspect-sensitive, the power scattered in slightly off-orthogonal directions can be scattered again into directions further from orthogonality and so on, resulting in reduced aspect sensitivity in the backscatter received from the irregular region as a whole.

We should emphasise that our estimate of the aspect sensitivity leading to only a $10-\mathrm{dB}$ reduction in backscatter power at $3^{\circ}$ off-orthogonal is based on the assumption of extremely short irregularities so that there is no contribution to the backscatter power from altitudes other than that of UHR. Since this is unlikely to be realistic, contributions from other altitudes will mitigate the fall in the contribution from the UHR altitude when viewing this altitude off orthogonality. In this sense, our estimate is therefore a lower bound on the aspect sensitivity and the irregularities may be more aspectsensitive than it suggests.

The observations presented here rely on natural variations in the altitude of upper-hybrid resonance due to TIDs. In order to investigate how the altitude of irregularities affects HF radar observations more systematically, it would be possible to create controlled altitude variations by varying the HF pump frequency so that the UHR altitude is varied. In this way, the uncertainty in the electron density distribution created by the presence of TIDs and which limits the reliability with which we can trace the radar propagation, is avoided. Of course, it is possible that varying the pump frequency might itself lead to differences in the characteristics of the irregularities.

Finally, it is worth noting that our raytracing simulations of the HF radar propagation show that, even in the case of the large amplitude TID E, the perturbations to the radar rays are not too great. This is particularly true at $18 \mathrm{MHz}$ where ionospheric refraction is less than at $13 \mathrm{MHz}$. Thus, to a first approximation, the effects of the TID on the radar propagation can be ignored as far as artificial backscatter is concerned and the effect of the TID on the HF pump wave propagation is much more important. This means that the elevation angle variations are not likely to be caused by the distortion of the radar propagation associated with the TID, but by changes in the location of the target, as we have assumed up to now. Of course, the effect of a TID on the radar propagation is not insignificant when considering the perturbations to the skip distance.

\section{Conclusions}

By comparing multi-instrument observations, we have identified perturbations in the location and intensity of artificial HF radar backscatter as being caused by the passage of TIDs through the pumped volume of plasma. The presence of atmospheric gravity wave-induced TIDs was inferred from the skip distance variation in the HF radar measurements and the electron density perturbations measured by incoherent scatter radar. A raytracing model of the HF pump wave propagation allows us to understand some of the HF radar phenomena in terms of the modification of the region of the ionosphere in which the pump wave can reach the upperhybrid resonance level where the irregularities are excited. In particular we can understand the extensions of the artificial backscatter region as being related to the increased altitude of UHR when the disturbance travels over the pump transmitter and an erosion of the poleward edge of the region as being due to the pump being unable to access the UHR altitude in that region. According to both data and modelling, these effects become more pronounced as the amplitude of the TID (in terms of relative electron density perturbation) increases.

We can see that it is possible to determine from the artificial backscatter observations alone, the period and the lineof-sight phase speed component of the TID and therefore the horizontal wavelength. Furthermore, with the aid of a raytracing model, it would be possible to estimate the TID amplitude and vertical wavelength by fitting the model to the observations. In this way, observations of TIDs in artificial backscatter can be used to support observations based on ground scatter skip distance variations. The artificial irregularities are in-situ tracers of the ionospheric distortions caused by a TID and thus represent a more direct means of accessing TID parameters than inverting ground scatter measurements.

As for the irregularities themselves, our observations, particularly the elevation angle variations, suggest that offorthogonal scattering may be important. Thus the assumption of near-infinite aspect sensitivity may not always be justified. This means that the results of analyses like those carried out by Senior et al. (2004) must be treated with some caution, but equally our conclusions here are subject to some doubt over the accuracy of the elevation angles measured. The aspect-sensitivity of the irregularities is an indicator of their small-scale field-parallel structure, which could arise from the dynamic equilibrium between growth from the heating caused by upper-hybrid waves and their destruction by, for example, drift waves excited by the field-transverse temperature and density gradients. We have suggested that the aspect-sensitivity should be investigated further by carrying out experiments in which the height of the irregularities is varied in a controlled manner by varying the HF pump frequency. 
Acknowledgements. This work was supported by UK Particle Physics and Astronomy Research Council (PPARC) grants PPA/G/S/2001/00070 and PP/C000218/1. The CUTLASS radars are operated by the University of Leicester; we thank members of the Radio and Space Plasma Physics Group at Leicester for operating the radar. The $K_{p}$ and $D_{s t}$ indices were obtained via the UK Solar System Data Centre (UKSSDC). Both CUTLASS and UKSSDC are PPARC National Facilities for Solar Terrestrial Physics. EISCAT is an International Association supported by Finland (SA), France (CNRS), Germany (MPG), Japan (NIPR), Norway (NFR), Sweden (VR) and the United Kingdom (PPARC).

Topical Editor M. Pinnock thanks T. B. Leyser and another referee for their help in evaluating this paper.

\section{References}

Antani, S. N. and Guzdar, P. N.: Excitation of short-scale density structures by drift waves during ionospheric heating, Geophys. Res. Lett., 26, 3285-3288, 1999.

Arnold, N. F., Jones, T. B., Robinson, T. R., Stocker, A. J., and Davies, J. A.: Validation of the CUTLASS HF radar gravity wave observing capability using EISCAT CP-1 data, Ann. Geophys., 16, 1392-1399, 1998,

http://www.ann-geophys.net/16/1392/1998/.

Blagoveshchenskaya, N. F. and Troshichev, O. A.: Ionospheric phenomena produced by modification experiments, J. Atmos. Terr. Phys., 58, 397-406, 1996.

Bond, G. E., Robinson, T. R., Eglitis, P., Wright, D. M., Stocker, A. J., Rietveld, M. T., and Jones, T. B.: Spatial observations by the CUTLASS coherent scatter radar of ionospheric modification by high power radio waves, Ann. Geophys., 15, 1412-1421, 1997 ,

http://www.ann-geophys.net/15/1412/1997/.

Booker, H. G.: A theory of scattering by nonisotropic irregularities with application to radar reflections from the aurora, J. Atmos. Terr. Phys., 8, 204-221, 1956.

Borisov, N.: Excitation of a drift instability in the ionosphere illuminated by powerful radio waves, Phys. Lett. A, 330, 107-112, 2004.

Bristow, W. A. and Greenwald, R. A.: Estimating gravity wave parameters from oblique high-frequency backscatter: modeling and analysis, J. Geophys. Res., 100, 3639-3648, 1995.

Chimonas, G. and Hines, C. O.: Atmospheric gravity waves launched by auroral currents, Planet. Space Sci., 18, 565-582, 1970.

Das, A. C. and Fejer, J. A.: Resonance instability of small-scale field-aligned irregularities, J. Geophys. Res., 84, 6701-6704, 1979.

Davies, K.: Ionospheric Radio Propagation, United States Department of Commerce, National Bureau of Standards, 1965.

Dysthe, K. B., Mjølhus, E., Pécseli, H., and Rypdal, K.: Thermal cavitons, Phys. Scr., T2/2, 548-559, 1982.

Dysthe, K. B., Mjølhus, E., Pécseli, H. L., and Rypdal, K.: A thermal oscillating two-stream instability, Phys. Fluids, 26, 146-157, 1983.

Fialer, P. A.: Field-aligned scattering from a heated region of the ionosphere - Observations at HF and VHF, Radio Sci., 9, 923940, 1974.
Francis, S. H.: A theory of medium-scale traveling ionospheric disturbances, J. Geophys. Res., 79, 5245-5260, 1974.

Francis, S. H.: Global propagation of atmospheric gravity waves: A review, J. Atmos. Terr. Phys., 37, 1011-1054, 1975.

Franz, T. L., Kelley, M. C., and Gurevich, A. V.: Radar backscattering from artificial field-aligned irregularities, Radio Sci., 34, 465-475, 1999.

Georges, T. M. and Stephenson, J. J.: HF radar signatures of traveling ionospheric irregularities, 3D ray-tracing simulation, Radio Sci., 4, 679-696, 1969.

Gurevich, A. V.: Nonlinear Phenomena in the Ionosphere, Springer Verlag, New York, 1978.

Gurevich, A. V., Lukyanov, A. V., and Zybin, K. B.: Stationary State of Isolated Striations Developed During Ionospheric Modification, Phys. Lett. A, 206, 247-259, 1995.

Hocke, K. and Schlegel, K.: A review of atmospheric gravity waves and travelling ionospheric disturbances: 1982-1995, Ann. Geophys., 14, 917-940, 1996, http://www.ann-geophys.net/14/917/1996/.

Hooke, W. H.: The ionospheric response to internal gravity waves, 1. The $F_{2}$ region response, J. Geophys. Res., 75, 5535-5544, 1970a.

Hooke, W. H.: Ionospheric repsonse to internal gravity waves, 2. Lower $F$ region response, J. Geophys. Res., 75, 7229-7238, 1970 b.

Huang, C.-S., Andre, D. A., and Sofko, G. J.: High-latitude ionospheric perturbations and gravity waves 2 . Numerical simulations, J. Geophys. Res., 103, 2143-2153, 1998.

Hunsucker, R. D.: Atmospheric gravity waves generated in the high-latitude ionosphere: a review, Rev. Geophys. Space Phys., 20, 293-315, 1982.

Jones, R. M. and Stephenson, J. J.: A versatile three-dimensional ray tracing computer program for radio waves in the ionosphere, Tech. Rep. OT 75-76, Office of Telecommunications, U.S. Department of Commerce, 1975.

Jones, T. B., Robinson, T. R., Stubbe, P., and Kopka, H.: Frequency Dependence of Anomalous Absorption Caused by High Power Radio Waves, J. Atmos. Terr. Phys., 46, 147-153, 1984.

Kelley, M. C.: Evidence for drift waves in ionospheric heating experiments, Geophys. Res. Lett., 31, L11806, doi:10.1029/2004GL020105, 2004.

Kelley, M. C., Arce, T. L., Salowey, J., Sulzer, M., Armstrong, W. T., Carter, M., and Duncan, L.: Density Depletions at the $10 \mathrm{~m}$ Scale Induced by the Arecibo Heater, J. Geophys. Res., 100, 17367-17376, 1995.

Kirchengast, G., Hocke, K., and Schlegel, K.: The gravity waveTID relationship: insight via theoretical model-EISCAT data comparison, J. Atmos. Terr. Phys., 58, 233-243, 1996.

Lester, M., Chapman, P. J., Cowley, S. W. H., Crooks, S. J., Davies, J. A., Hamadyk, P., McWilliams, K. A., Milan, S. E., Parsons, M. J., Payne, D. B., Thomas, E. C., Thornhill, J. D., Wade, N. M., Yeoman, T. K., and Barnes, R. J.: Stereo CUTLASS - A new capability for the SuperDARN HF radars, Ann. Geophys., 22, 459-473, 2004, http://www.ann-geophys.net/22/459/2004/.

Mayr, H. H., Harris, I., Herrero, F. A., Spencer, N. W., Varosi, F., and Pesnell, W. D.: Thermospheric gravity waves: observations and interpretation using the transfer function model (TEM), Space Sci. Rev., 54, 297-375, 1990. 
Milan, S. E., Jones, T. B., Robinson, T. R., Thomas, E. C., and Yeoman, T. K.: Interferometric evidence for the observation of ground backscatter originating behind the CUTLASS coherent HF radars, Ann. Geophys., 15, 29-39, 1997, http://www.ann-geophys.net/15/29/1997/.

Minkoff, J., Kugelman, P., and Weissman, I.: Radio Frequency Scattering from a Heated Ionospheric Volume, VHF/UHF Fieldaligned and Plasma-line Backscatter Measurements, Radio Sci., 9, 941-956, 1974.

Mjølhus, E.: On reflexion and trapping of upper-hybrid waves, J. Plasma Phys., 29, 195-215, 1983.

Rietveld, M. T., Kohl, H., Kopka, H., and Stubbe, P.: Introduction to ionospheric heating experiments at Troms $\varnothing-$ I. Experimental overview, J. Atmos. Terr. Phys., 55, 577-599, 1993.

Rishbeth, H. and van Eyken, A. P.: EISCAT - Early history and the first ten years of operation, J. Atmos. Terr. Phys., 55, 525-542, 1993.

Robinson, T. R.: The heating of the high latitude ionosphere by high power radio waves, Phys. Rep., 179, 79-209, 1989.

Robinson, T. R., Stocker, A., Bond, G., Eglitis, P., Wright, D., Jones, T. B., and Rietveld, M. T.: First CUTLASS-EISCAT heating results, Adv. Space Res., 21, 663-666, 1998.

Samson, J. C., Greenwald, R. A., Ruohoniemi, J. M., Frey, A., and Baker, K. B.: Goose Bay radar observations of earth-reflected, atmospheric gravity waves in the high-latitude ionosphere, J. Geophys. Res., 95, 7693-7709, 1990.

Schlegel, K.: The study of tides and gravity waves with the help of field-aligned velocities measured by EISCAT, J. Atmos. Terr. Phys., 48, 879-886, 1986.
Senior, A., Borisov, N. D., Kosch, M. J., Yeoman, T. K., Honary, F., and Rietveld, M. T.: Multi-frequency HF radar measurements of artificial F-region field-aligned irregularities, Ann. Geophys., 22, 3503-3511, 2004, http://www.ann-geophys.net/22/3503/2004/.

Shibata, T. and Schlegel, K.: Vertical structure of AGW associated ionospheric fluctuations in the E- and lower F-region observed with EISCAT - a case study, J. Atmos. Terr. Phys., 55, 739-749, 1993.

Stubbe, P., Kohl, H., and Rietveld, M. T.: Langmuir turbulence and ionospheric modification, J. Geophys. Res., 97, 6285-6297, 1992.

Thome, G. D. and Blood, D. W.: First observations of RF backscatter from field-aligned irregularities produced by ionospheric heating, Radio Sci., 9, 917-921, 1974.

Yeh, K. C. and Liu, C. H.: Acoustic-gravity waves in the upper atmosphere, Rev. Geophys. Space Phys., 12, 193-216, 1974.

Yeoman, T. K. and Wright, D. M.: ULF waves with drift resonance and drift-bounce resonance energy sources as observed in artificially-induced HF radar backscatter, Ann. Geophys., 19, 159-170, 2001, http://www.ann-geophys.net/19/159/2001/. 